\title{
INHIBITING EFFECTS OF L-TRYPTOPHAN ON THE CARBON STEEL CORROSION IN ALKALINE SALINE SOLUTION
}

\author{
Taghried A. Salman ${ }^{1, *}$ and Ala'a B. Mohammed \\ 1 ,*Department of Chemistry, College of Science, Al-Nahrain University, Baghdad, Iraq \\ "E-mail: dr.tag_s@yahoo.com
}

\begin{abstract}
The inhibiting effect of L-tryptophan, that considered as an eco-friendly compound on the corrosion of carbon steel in saline solution $(3.5 \% \mathrm{NaCl})$ at $\mathrm{pH} 11$ was investigated potentiostatically at five temperatures in the range 293 $313 \mathrm{~K}$. Five concentrations of inhibitor were tested ranging from $5 \times 10^{-4}$ to $1 \times 10^{-2} \mathrm{~mole}^{-1}$. The addition of $\mathrm{L}-$ tryptophan to alkaline sodium chloride solution lowered the corrosion feasibility of the alloy. On the other hand, the corrosion feasibility increased with the rise of temperature. Carbon steel corrosion rate in the saline solution was decreased on increasing L-tryptophan concentration reflecting the inhibiting effect of L-tryptophan when it is present at high concentration in the saline solution. The efficiency of inhibition (\% IE) of L-tryptophan increased with increasing the concentration of the inhibitor attaining a maximum value of $71.72 \%$ when the L-tryptophan concentration in the saline solution became $1 \times 10^{-2}$ mole $\mathrm{L}^{-1}$, and decrease with the rise of temperature. Adsorption of L-tryptophan on the surface of carbon steel was considered to obey Langmuir isotherm. Gibbs free energy of adsorption of L-tryptophan on steel was $-29.07 \mathrm{~kJ} \mathrm{~mol}^{-1}$ indicates a physisorption of the inhibitor on the surface of carbon steel alloy. Quantum mechanical study using DFT method with B3LYP/6-31G basis set was applied to achieve good relation between the inhibition efficiency and the chemical structure of L-tryptophan.
\end{abstract}

Keywords:Corrosion, Carbon Steel, saline solution,Adsorption,L-tryptophan, DFT method.

(c) RASĀYAN. All rights reserved

\section{INTRODUCTION}

Carbon steel is one of the most extensively used iron alloy in engineering material, tonnages in marine applications, chemical handling, manufacture of petroleum, purgation, construction and metal-processing equipment ${ }^{1}$. Protection of metals or alloys from corrosion were studied by using many techniques. The use of organic inhibitors containing a heteroatom, like oxygen, nitrogen, sulfur and multiple bonds is usually the most efficacious method for the protection of metals against corrosion in saline solution. The chosen of inhibitors selected by its economic availability, its efficiency to inhibit the substrate material and its environmental parameters ${ }^{2}$. On the other hand. most organic compounds are expensive and toxic to both human beings and environments, so the used of natural, Eco-friendly, cheap and nontoxic compounds are required ${ }^{3}$. Amino acids are low cost, non-toxic and highly soluble in aqueous media with high purity which adsorbed on the surface of a metal to reduce the rate of corrosion either by coverage effect of adsorbed inhibitor molecules on the metal surface and / or effect on the activation barriers of the anodic and cathodic reactions of the corrosion reaction ${ }^{4}$.

The well-known computational method that is used successfully to explain the chemical reactivity of inhibitors and their adsorption efficiency on the metal surface is density functional theory (DFT). This method is also providing suitable information to corrosion researchers in order to the investigation of corrosion inhibition mechanism theoretically. Such computations were widely used to analyze the molecular electronic structures of adsorbed inhibitors using a number of computational descriptors that give important insights into the mechanisms of corrosion inhibition. Consequently, inhibition efficiency corresponds to the molecular and structural properties of inhibitor compounds. These parameters which might be obtained through computational calculations that includes, chemical reactivity, charge distribution and the frontier molecular orbit theory, HOMO (higher occupied molecular orbital) energy, the LUMO (lower unoccupied molecular orbital) energy, the energy gap $(\Delta E)$, global hardness $(\eta)$, global softness $(\sigma)$, dipole moment $(\mu)$, electronegativity $(\chi)$ and electron transfer number $(\Delta N)^{5,6}$. 
This work aimed to investigate the effectiveness of L-tryptophan on the protection efficiency and kinetic of the carbon steel corrosion in saline solution at $\mathrm{pH} 11$. The chemical and optimize structures of L-tryptophan are presented in Fig.-1. A correlation was made between the corrosion inhibition potential and molecular structure of L-tryptophan using DFT method.

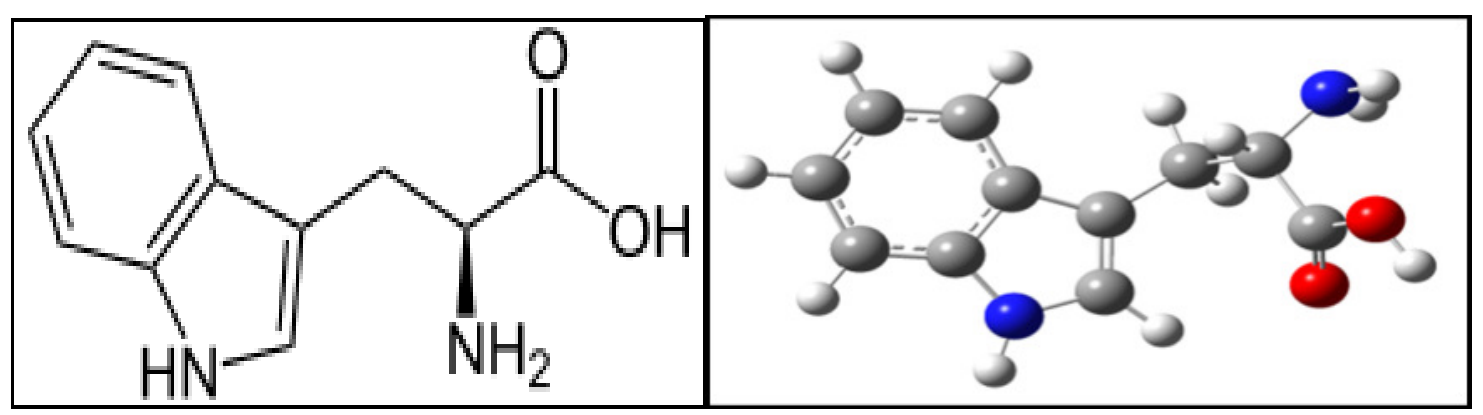

Fig.-1:The chemical and optimize structures of L-tryptophan.

\section{Sample Preparation}

\section{EXPERIMENTAL}

Carbon steel specimen has the following composition in weight percentage (P 0.018, Mo 0.03, Ni 0.017, $\mathrm{C} 0.19, \mathrm{Si} \mathrm{0.35,} \mathrm{Cr} 0.04, \mathrm{Cu} 0.02, \mathrm{Al} \mathrm{0.06}$, and the rest iron) as revealed by emission spectroscopic analysis. Analar grade chemicals $(\mathrm{NaCl}, \mathrm{NaOH}$ and L-tryptophan ) were used for the preparation of the solutions. Circular working electrode samples with $2.5 \mathrm{~cm}$ in diameter, $1 \mathrm{~mm}$ in thickness and with a surface area of $1 \mathrm{~cm}^{2}$ were polished to mirror finish with emery paper in various grades of 320,500, 1000,2400 and $4000 \mathrm{~mm}$, then with diamond product spray that contains ethanol with different size of diamond particles $(1,3,6,9) \mu \mathrm{m}$ and then washed with ethanol, acetone and finally rinsed with distilled water.

\section{Preparation of solutions}

1. $35 \mathrm{~g}$ of $\mathrm{NaCl}$ was dissolved in $1000 \mathrm{~mL}$ distilled water to prepare $3.5 \%$ of $\mathrm{NaCl}$ solution.

2. L-tryptophan was prepared in different concentrations $\left(5 \times 10^{-4}, 1 \times 10^{-3}, 5 \times 10^{-3}\right.$, and $\left.1 \times 10^{-2}\right) \mathrm{M}$ by dissolving appropriate amount in $1000 \mathrm{~mL}$ of $3.5 \% \mathrm{NaCl}$ solution at $\mathrm{pH} 11$.

3. $1 \mathrm{M} \mathrm{NaOH}$ solution was prepared to control the $\mathrm{pH}$ of the testing solution.

\section{Electrochemical studies}

Electrochemical measurements were performed by potentiodynamic polarization calculations that carried out in an electrochemical cell using three-electrode:

- Saturated Calomel Electrode (SCE) as a reference electrode.

- a platinum electrode as an auxiliary electrode.

- carbon steel alloy as a working electrode.

M Lab (WENKING MLab multichannel and SCI-MLab system for corrosion measurement obtained from Bank Electronics- Intelligent controls $\mathrm{GmbH}$, Germany 2007) is an instrument with high-tech for electrochemical measurements. M-Lab is worked by computer desktop Window XP.

\section{Theoretical Studies}

Gaussian 09W program was used to study the presence of a relation between computational results and the experimental inhibition efficiencies of L-tryptophan being corrosion inhibitor. Computational results were achieved by using DFT method with Beck's three parameter exchange functional along with Lee-Yang-Parr non-local correlation functional (B3LYP) and with 6-31G basis set. $\mathrm{E}_{\text {номо (highest }}$ occupied molecular orbital), $\mathrm{E}_{\mathrm{Lumo}}$ (lowest unoccupied molecular orbital), $\Delta \mathrm{E}$ (energy gap), $\mu$ (dipole 
moment), $\mathrm{E}_{\text {total }}$ (the total energy), $\chi$ (absolute electronegativity), $\gamma$ (global hardness) and $\Delta \mathrm{N}$ (the fraction of electrons transferred) were calculated by using the above given computer code package.

\section{Polarization Measurements}

\section{RESULTS AND DISCUSSION}

Table-1 presents the data obtained from the polarization curves for corrosion of carbon steel in 3.5\% $\mathrm{NaCl}$ solution at $\mathrm{pH} 11$ for blank and inhibited solution containing various concentrations of L-tryptophan at different five temperatures 293, 298,303,308 and 313 K (Fig.-2). Values of corrosion current density $\left(i_{\text {corr }}\right)$, corrosion potential $\left(\mathrm{E}_{\text {corr }}\right)$, cathodic $\left(\mathrm{b}_{\mathrm{c}}\right)$, and anodic $\left(\mathrm{b}_{\mathrm{a}}\right)$ Tafel slopes are given in Table-1.

The addition of L-tryptophan to saline solution $(3.5 \% \mathrm{NaCl})$ at $\mathrm{pH} 11$ caused an alteration in the corrosion potential ( $\mathrm{E}_{\text {corr. }}$ ) of carbon steel. The range of shifting is toward more negative potentials and the effect became more intense with increasing concentration of inhibitor (Table-1). This is interpreted on the basis of the decreasing corrosion feasibility in the existence of L-tryptophan and also by its increasing concentration in the saline solution, this indicated that L-tryptophan acts more cathodic than an anodic inhibitor.

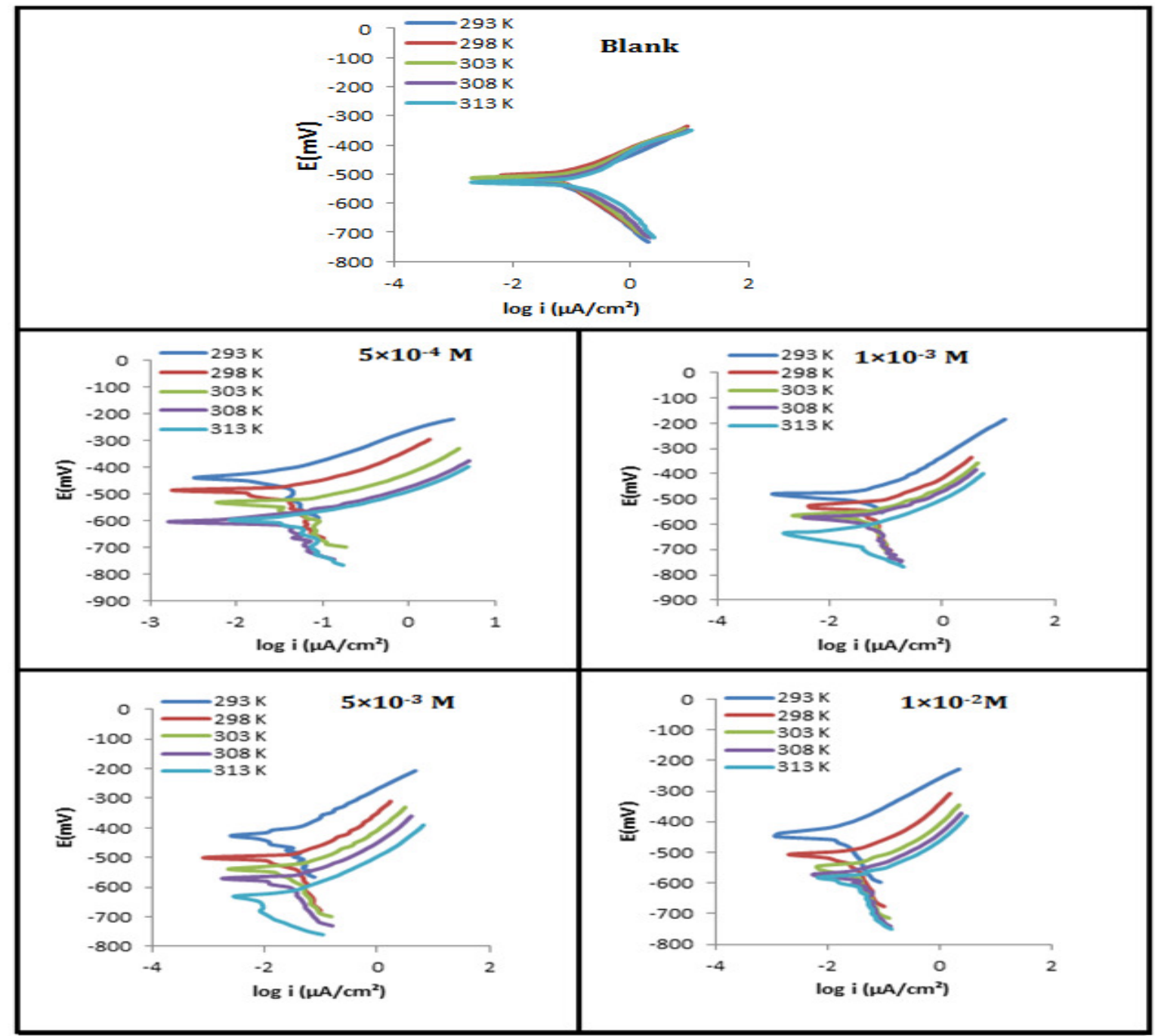

Fig.-2: Polarization curves for carbon steel corrosion in $3.5 \% \mathrm{NaCl}$ at $\mathrm{pH} 11$ for blank and inhibited solution containing various L-tryptophan concentrations at different temperatures in the range (293-313)K. 
RASĀYAN J. Chem.

Vol. 10 | No. 3 |815 - 824 | July - September | 2017

At a constant L-tryptophan concentration, $\mathrm{E}_{\mathrm{corr}}$ values moved to more negative potential with increasing temperature. Thus, corrosion became more feasible with the rise of temperature (Table-1). The corrosion rate as reflected in the values of the corrosion current density $\left(i_{\text {corr }}\right)$ decreased at $293 \mathrm{~K}$ with increasing L-tryptophan concentration in the saline solution as shown in Table-1. At high concentrations of L-tryptophan, $i_{\text {corr }}$ began to decrease. At a constant L-tryptophan concentration in the saline solution, corrosion rate as reflected in the values of $i_{\text {corr }}$ (Table-1) increased with the rise of temperature. The corrosion current density $\left(i_{\text {corr }}\right)$ values are decreased with increasing inhibitor concentration. The $i_{\text {corr }}$ values increases, whereas the protection efficiencies (\% IE) values decrease with elevation temperature. The maximum inhibition efficiency $71.7 \%$ was achieved at the highest L-tryptophan concentration of $1 \times 10^{-2} \mathrm{M}$ and at $293 \mathrm{~K}$.

Values of Tafel slopes (cathodic and anodic) are varied at all L-tryptophan concentrations and temperatures (Table-1). These results refer to the variation of the rate-determining step from charge transfer process to either chemical deposition or to electrochemical desorption in the cathodic reactions and also to the variation of this step in dissolution reaction of carbon steel alloy ${ }^{7}$.

Table-1: Corrosion parameters of carbon steel in $3.5 \% \mathrm{NaCl}$ at $\mathrm{pH} 11$ for blank and inhibited solution containing various L-tryptophan concentrations $\left(5 \times 10^{-4}, 1 \times 10^{-3}, 5 \times 10^{-3}\right.$ and $\left.1 \times 10^{-2}\right) \mathrm{M}$ at different temperatures in the range $(293-313) \mathrm{K}$..

\begin{tabular}{|c|c|c|c|c|c|c|c|}
\hline \multirow[t]{2}{*}{$\begin{array}{l}\text { Inh. } \\
{[\mathrm{M}]}\end{array}$} & \multirow[t]{2}{*}{$\begin{array}{c}\mathrm{T} \\
{[\mathrm{K}]}\end{array}$} & \multirow[t]{2}{*}{$\begin{array}{l}-\mathrm{E}_{\mathrm{corr}} \\
{[\mathrm{mV}]}\end{array}$} & \multirow[t]{2}{*}{$\begin{array}{c}\mathrm{i}_{\text {corr }} \\
{\left[\mu \mathrm{A} / \mathrm{cm}^{2}\right]}\end{array}$} & \multicolumn{2}{|c|}{$\begin{array}{c}\text { Tafel slope } \\
{[\mathrm{mV} / \mathrm{dec}]}\end{array}$} & \multirow[t]{2}{*}{$\theta$} & \multirow[t]{2}{*}{$\% \mathrm{IE}$} \\
\hline & & & & $-b_{c}$ & $+b_{a}$ & & \\
\hline \multirow{5}{*}{0} & 293 & 507.1 & 51.09 & 92.5 & 62.6 & - & - \\
\hline & 298 & 513.9 & 55.67 & 136.7 & 73.2 & - & - \\
\hline & 303 & 516.8 & 66.99 & 120.9 & 81.3 & - & - \\
\hline & 308 & 525.8 & 87.14 & 107.0 & 95.1 & - & - \\
\hline & 313 & 530.3 & 92.28 & 103.5 & 91.9 & - & - \\
\hline \multirow{5}{*}{$\begin{array}{l}\underset{0}{0} \\
\underset{x}{x} \\
n\end{array}$} & 293 & 437.5 & 22.78 & 269.6 & 102.1 & 0.554 & 55.41 \\
\hline & 298 & 488.5 & 25.77 & 262.9 & 77.7 & 0.537 & 53.71 \\
\hline & 303 & 537.0 & 32.91 & 179.3 & 68.1 & 0.509 & 50.87 \\
\hline & 308 & 585.3 & 43.13 & 339.5 & 74.2 & 0.505 & 50.50 \\
\hline & 313 & 598.6 & 48.07 & 277.6 & 77.6 & 0.479 & 47.91 \\
\hline \multirow{5}{*}{ 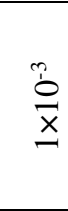 } & 293 & 486.8 & 20.09 & 94.30 & 68.8 & 0.607 & 60.68 \\
\hline & 298 & 533.7 & 24.30 & 139.3 & 58.8 & 0.564 & 56.35 \\
\hline & 303 & 565.1 & 31.15 & 259.8 & 71.2 & 0.535 & 53.50 \\
\hline & 308 & 579.5 & 41.95 & 167.2 & 69.8 & 0.519 & 51.86 \\
\hline & 313 & 629.4 & 45.22 & 285.6 & 86.1 & 0.510 & 51.00 \\
\hline \multirow{5}{*}{$\underset{n}{\vec{x}}$} & 293 & 433.3 & 19.40 & 191.5 & 96.1 & 0.620 & 62.03 \\
\hline & 298 & 504.6 & 22.88 & 179.3 & 71.2 & 0.589 & 58.90 \\
\hline & 303 & 538.8 & 28.76 & 339.9 & 74.6 & 0.571 & 57.07 \\
\hline & 308 & 576.6 & 38.47 & 285.9 & 75.8 & 0.559 & 55.85 \\
\hline & 313 & 624.2 & 42.84 & 235.5 & 75.4 & 0.536 & 53.58 \\
\hline \multirow{5}{*}{ 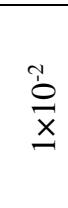 } & 293 & 436.6 & 14.45 & 135.9 & 83.7 & 0.717 & 71.72 \\
\hline & 298 & 510.4 & 18.85 & 155.9 & 79.2 & 0.661 & 66.14 \\
\hline & 303 & 544.4 & 24.28 & 343.4 & 68.7 & 0.638 & 63.76 \\
\hline & 308 & 572.9 & 33.05 & 134.8 & 84.9 & 0.621 & 62.07 \\
\hline & 313 & 588.4 & 38.16 & 256.1 & 79.5 & 0.587 & 58.65 \\
\hline
\end{tabular}

\section{Corrosion Protection}

The protection efficiency (\%IE) of L-tryptophan in inhibiting carbon steel corrosion in $3.5 \% \mathrm{NaCl}$ solution at $\mathrm{pH} 11$ was determined from the equation ${ }^{8}$ :

$$
\% I E=\frac{i_{\text {LarT }}^{a}-i_{\text {LarT }}}{i_{\text {rarT }}^{0}} \times 100
$$


Where, $i_{\text {corr }}^{\mathrm{o}}$ and $i_{\text {corr }}$ are respectively the corrosion current density for black and inhibited saline solution containing various L-tryptophan concentrations at the same temperature. The calculated values of \%IE, for the different tryptophan concentrations and temperatures, are given in Table- 1 . At $293 \mathrm{~K}$, the corrosion protection (\% IE) by L-tryptophan increased with increasing its concentration, attaining a maximum of $71.72 \%$ when L-tryptophan concentration became $1 \times 10^{-2}$ mole. $L^{-1}$ in the saline solution (Table-1).

The coverage $(\theta)$ of carbon steel's surface by the adsorbed L-tryptophan is estimated from the current density $(i)$ at constant applied potential $(\mathrm{E})$ for blank $\left(i_{\text {corr }}\right)$ and inhibited saline solution $\left(i_{\text {corr(inhi) }}\right)$ containing various concentrations of L-tryptophan by using this relation ${ }^{9}$ :

$$
\theta=\frac{i_{\text {raTr }}-i_{\text {rarr }[\text { inhis }}}{i_{\text {Eor }}}
$$

\section{Kinetics of Corrosion}

The dependence of $\left(i_{\text {corr }}\right)$ values on temperature was examined by plotting $\log \left(i_{\text {corr }}\right)$ versus $1 / T$ for the various L-tryptophan concentrations in saline solution in accordance with the Arrhenius equation ${ }^{10}$ :

$$
i_{\text {corr }}=\operatorname{Aexp}\left(\frac{-E_{a}}{R T}\right)
$$

Where $i_{\text {corr }}$ stands for the rate of corrosion at temperature T. Activation energy $\left(\mathrm{E}_{\mathrm{a}}\right)$ and the preexponential factor (A) data were obtained from the slopes and intercept respectively $\log \left(i_{\text {corr }}\right)$ versus $1 / \mathrm{T}$ plots as shown in Figure-3.The resulting values of $\left(E_{a}\right)$ and $(A)$ are given in Table-2. It is noted that the activation energy $\left(E_{a}\right)$ is higher in the presence of the inhibitors than in blank solution and it will increase with increasing concentration of inhibitor due to adsorption of inhibitor molecules on the metal surface, and it decreases with increasing the temperature, at high temperature occurs desorption of inhibitor molecule so the metal surface exposed to corrosion. A relatively higher value of $\left(E_{a}\right)$ in the presence of Ltryptophan is combined with relatively higher pre-exponential factor $\mathrm{A}$ as compared with the corresponding values of $\left(E_{a}\right)$ and $(A)$ in the absence of the inhibitor.Thus, a high value of $\left(E_{a}\right)$ is connected with a high value of (A) and the reverse is also true. This effect was ascribed to the presence of energetically heterogeneous reaction sites on the carbon steel surface.

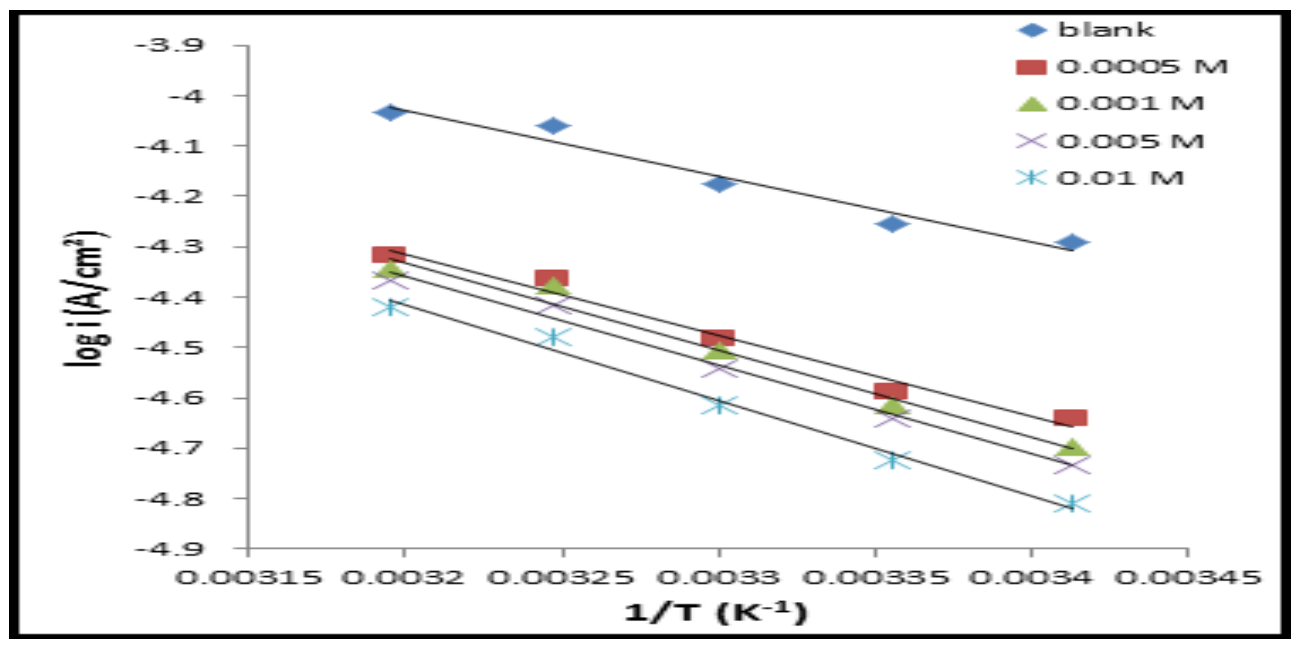

Fig.-3: $\log \mathrm{i}_{\text {corr }}$ versus 1/T of carbon steel corrosion in 3.5\% $\mathrm{NaCl}$ at $\mathrm{pH} 11$ solution for blank and inhibited solution containing various L-tryptophan concentrations.

Enthalpy $(\Delta \mathrm{H})$ and entropy $(\Delta \mathrm{S})$ of activation were calculated from the transition state of a replacement formulation of Arrhenius equation that expressed as ${ }^{11}$ :

$$
i_{\text {corr }}=\left(\frac{K T}{N h}\right) \exp \left(\frac{\Delta S}{R}\right) \exp \left(\frac{-\Delta H}{K T}\right)
$$


Where, $i_{\text {corr }}$ is the corrosion current density, $\mathrm{N}$ is the Avogadro number, $\mathrm{h}$ is the Planck's constant, $\mathrm{R}$ is the molar gas constant and $\mathrm{T}$ is the absolute temperature. Equation (4) may be rearranged into linear form as :

$$
\ln _{\text {com }}=\left(\frac{-\Delta H}{R}\right)\left(\frac{1}{T}\right)+\left[\ln \left(\frac{R}{N h}\right)+\left(\frac{\Delta S}{R}\right)\right]
$$

$\Delta \mathrm{H}$ and $\Delta \mathrm{S}$ values were obtained respectively, from the slope and intercept of the plot of $\ln i_{\text {corr }}$ against $1 / \mathrm{T}$ as show in Fig.-4, and the data obtained are given in Table-3. Values of activation enthalpies $(\Delta \mathrm{H})$ were positive and the positivity increased with increasing L-tryptophan concentration. The positive values of $\Delta \mathrm{H}$ in the absence and presence of the L-tryptophan indicates the endothermic nature of the carbon steel dissolution process. The entropy of activation $(\Delta S)$ data are negative and negativity decreased with increasing L-tryptophan concentration. The negative values of $\Delta \mathrm{S}$ reveal that the activated complex in the rate determining step represents association rather than the dissociation step, this means a decrease in disorder take place ${ }^{12,13}$.

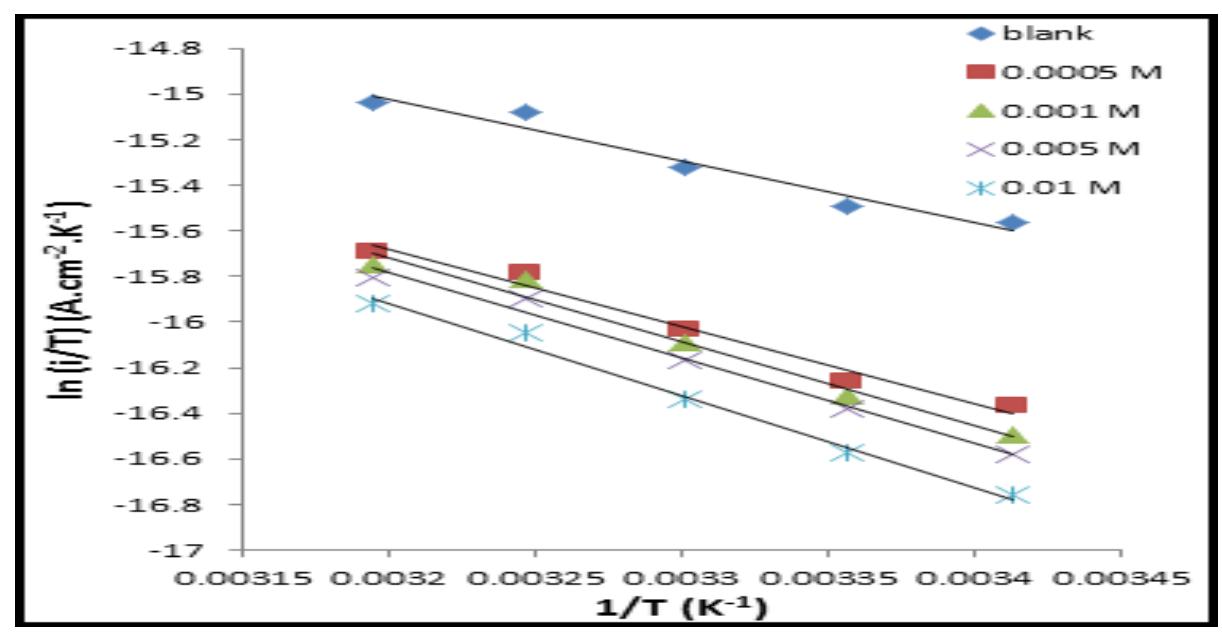

Fig.-4: Plots of $\mathrm{Ln}\left(i_{\text {corr }} / \mathrm{T}\right)$ versus $1 / \mathrm{T}$ for carbon steel in $3.5 \% \mathrm{NaCl}$ at $\mathrm{pH} 11$ solution for blank and inhibited solution containing various L-tryptophan concentrations.

\section{Adsorption Isotherm}

The interaction type between carbon steel surface and L-tryptophan molecules were explained by using Langmuir isotherm as expressed by the following linear equation ${ }^{14}$ :

$$
\left(\frac{C_{\mathrm{inh}}}{\theta}\right)=\frac{1}{K_{\mathrm{ad} s}}+C_{\mathrm{inh}}
$$

$\mathrm{C}_{\mathrm{inh}}$ is the L-tryptophan concentration and $\mathrm{K}_{\mathrm{ads}}$ is the adsorption-desorption equilibrium constant. Values of $\mathrm{C}_{\mathrm{inh}} / \theta$ for L-tryptophan in the saline solution were ploted against the corresponding values of the inhibitor concentration $\left(\mathrm{C}_{\text {inh }}\right)$ as shown in Fig. -5 and the relationships obtained were linear. The intercept of each plot on $\mathrm{C}_{\mathrm{inh}} / \theta$ axis is equal to $1 / \mathrm{K}_{\mathrm{ads}}$.

Table-3: Activation energy $\left(\mathrm{E}_{\mathrm{a}}\right)$, enthalpy $\left(\Delta \mathrm{H}_{\mathrm{a}}\right)$, and entropy $\left(\Delta \mathrm{S}_{\mathrm{a}}\right)$ of activation for the corrosion of carbon steel in $3.5 \% \mathrm{NaCl}$ aqueous solution at $\mathrm{pH} 11$ in the absence and presence of different concentration of Ltryptophan at $(293,298,303,308$ and 313$) \mathrm{K}$.

\begin{tabular}{c|c|c|c|c}
\hline $\begin{array}{c}\text { Con. } \\
{[\mathrm{M}]}\end{array}$ & $\begin{array}{c}\mathrm{E}_{\mathrm{a}} \\
{\left[\mathrm{kJ} \cdot \mathrm{mol}^{-1}\right]}\end{array}$ & $\begin{array}{c}\mathrm{A} \times 10^{24} \\
{[\text { molecule.cm }}\end{array}$ & $\begin{array}{c}\Delta \mathrm{H}_{\mathrm{a}} \\
{\left[\mathrm{kJ} \cdot \mathrm{mol}^{-1}\right]}\end{array}$ & $\begin{array}{c}-\Delta \mathrm{s}_{\mathrm{a}} \\
{\left[\mathrm{J} \cdot \mathrm{K}^{-1} \cdot \mathrm{mol}^{-1}\right]}\end{array}$ \\
\hline- & 24.86 & 0.801 & 22.34 & 250.98 \\
\hline $5 \times 10^{-4}$ & 30.63 & 3.82 & 28.10 & 237.98 \\
\hline $1 \times 10^{-3}$ & 33.11 & 9.60 & 30.59 & 230.32 \\
\hline
\end{tabular}


RASĀYAN J. Chem.

Vol. 10 | No. 3 |815 - 824 | July - September | 2017

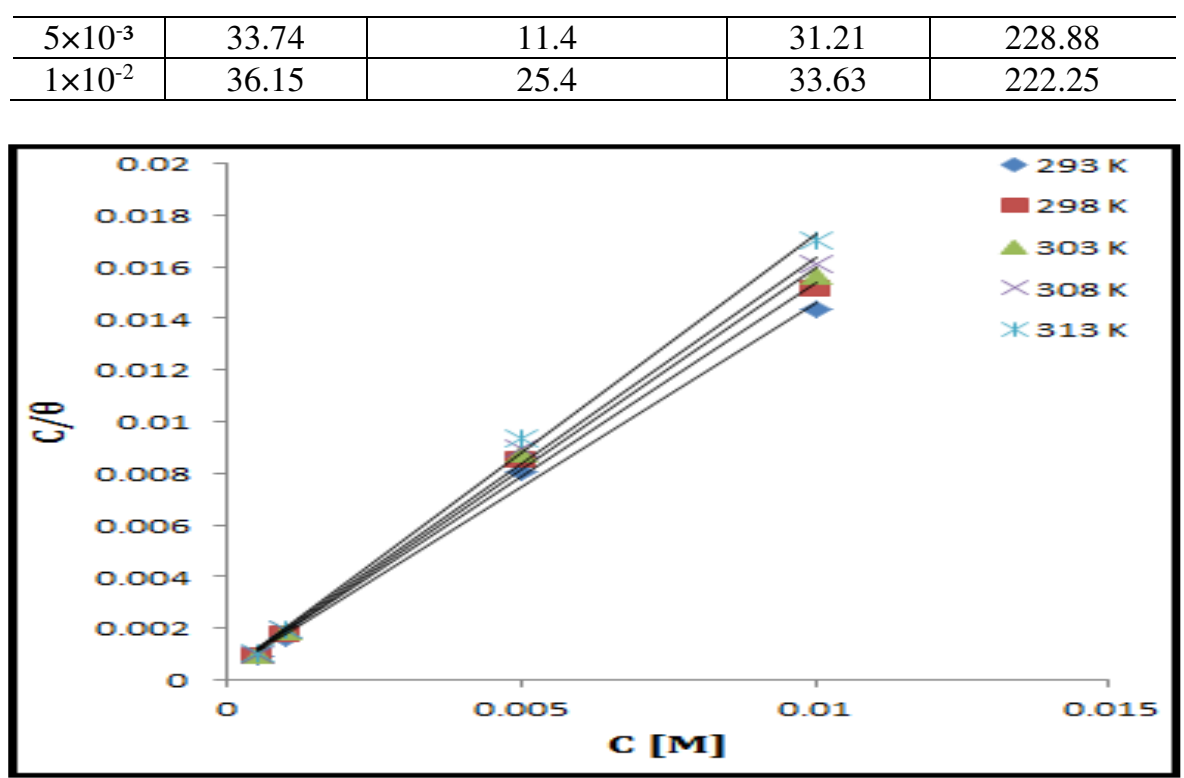

Fig.-6: Langmuir isotherm plots for the adsorption of L-tryptophan on the surface of carbon steel.

Using $\mathrm{K}_{\mathrm{ads}}$ values we can calculate the values of $\Delta \mathrm{G}_{\text {ads }}^{\circ}$ through the following equation:

$$
\Delta \mathrm{G}^{\circ}{ }_{a d z}=-R T h\left(55.5 K_{a d z}\right)
$$

$\Delta \mathrm{G}^{\circ}$ ads are adsorption Gibbs free energy of L-tryptophan at Temperature. 55.5 is the concentration of water in solution in mol/L. Values of $\mathrm{K}_{\text {ads }}$ and are tabulated in Table-4. The negative sign of $\Delta \mathrm{G}^{\circ}$ ads values indicated that the adsorption of inhibitors to form a stable adsorbed protective layer on carbon steel was spontaneous. $\Delta \mathrm{G}_{\text {ads }}^{\circ}$ values are ranging from $-31.02 \mathrm{~kJ} \mathrm{~mol}^{-1}$ to $-29.07 \mathrm{~kJ} \cdot \mathrm{mol}^{-1}$ for L-tryptophan at the temperature range $293 \mathrm{~K}$ to $313 \mathrm{~K}$. The values of $\Delta \mathrm{G}_{\text {ads }}^{\circ}$ ranging between $-40^{1}$ to $-20 \mathrm{~kJ} . \mathrm{mol}^{-1}$ meaning that the adsorption of these molecules involves chemisorptions as well as physisorption ${ }^{15,16}$. The molecular structure of the amino acid investigates indicates that they have strong potential to become an effective corrosion inhibitor due to the presence of nitrogen atom that is a derivative of indole. The results show also, that L-tryptophan adsorbed on the surface of carbon steel and fill the empty orbital of it through the indole ring with $\pi$-electrons, nitrogen and oxygen atoms and with the lone pair electrons in its molecule ${ }^{7}$.Adsorption Gibbs free energy change $\left(\Delta \mathrm{G}^{\circ}\right.$ ads $)$ data were plotted versus temperature $(T)$ in order to evaluate enthalpy change $\left(\Delta \mathrm{H}^{\circ}\right.$ ads $)$ and entropy change $\left(\Delta \mathrm{S}_{\text {ads }}{ }\right)$ of adsorption process according to the following equation:

$$
\Delta \mathrm{G}_{\text {ads }}^{\circ}=\Delta \mathrm{H}^{\circ} \text { ads }-\mathrm{T} \Delta \mathrm{S}_{\text {ads }}^{\circ}
$$

Where, $\Delta \mathrm{H}^{\circ}$ ads and $\Delta \mathrm{S}^{\circ}$ ads are respectively, the slope and intercept of linear relation as indicated in Fig.-7, and the data obtained are given in Table-4. The negative value of $\left(\Delta \mathrm{H}^{\circ}\right.$ ads $)$ shows that the adsorption process of L-tryptophan on the carbon steel surface is exothermic in nature. The value of the entropy change of activation $\left(\Delta \mathrm{S}_{\text {ads }}^{\circ}\right)$ is positive, this indicates an increase in randomness during the adsorption process $^{17}$.

\section{Computational Study}

Quantum chemical calculations of L-tryptophan molecule were achived by using DFT that based on the following relations ${ }^{18}$ :

$$
\begin{aligned}
& \chi=\frac{(I+A)}{2} \\
& \gamma=\frac{(I-A)}{2}
\end{aligned}
$$


Where $\chi$ is absolute electronegativity and $\gamma$ is global hardness. According to Koopman's theorem, the $\mathrm{E}_{\text {Hомо }}$ and $\mathrm{E}_{\mathrm{Lumo}}$ of the inhibitor molecule are represent the ionization potential (I), and the electron affinity (A), respectively, according to the following relations ${ }^{18}$ :

$$
\mathrm{I}=-\mathrm{E}_{\text {Hомо }}, \quad \mathrm{A}=-\mathrm{E}_{\mathrm{LUMO}}
$$

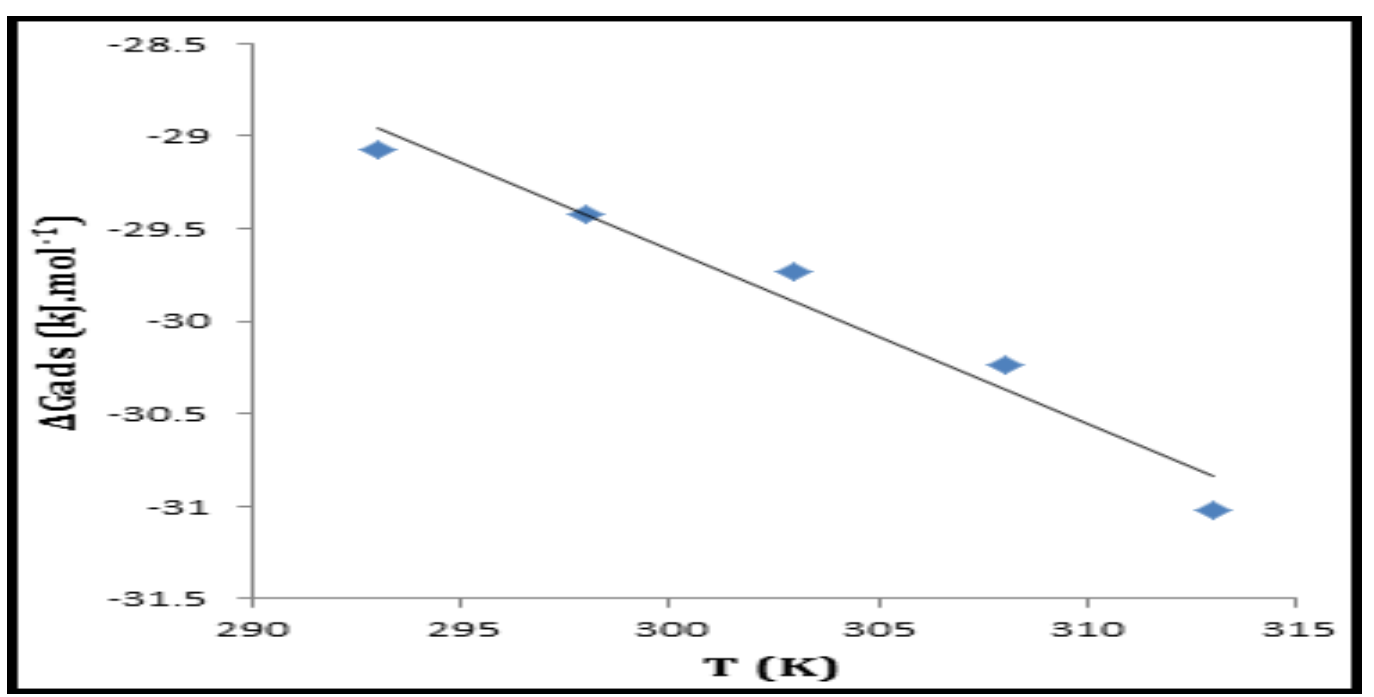

Fig.-7: The changing of Gibbs free energies $\left(\Delta \mathrm{G}_{\mathrm{ads}}\right)$ with temperature.

The fraction of electrons transferred $(\Delta \mathrm{N})$ was then calculated from this relation ${ }^{19}$ :

$$
\Delta N=\frac{\left(X_{F g}-X_{i n h}\right)}{2\left(\eta_{F s}+\eta_{\operatorname{minh}}\right)}
$$

Where $\chi_{\mathrm{Fe}} \approx 7.0 \mathrm{eV}$ is a theoretical value of iron and $\eta_{\mathrm{Fe}}=0$ is taken assuming that $\mathrm{I}=\mathrm{A}$ for bulk metals. The higher value of $\Delta \mathrm{N}$ indicates higher inhibition efficiency of the inhibitor (L-tryptophan) and the higher value of dipole moment indicates that L-Tryptophan is aromatic compound can donate electrons to form strong bond ${ }^{19}$. literature survey shows that the adsorption of the inhibitor on the metal surface basis of the donor-acceptor interactions between the $\pi$-electrons of the heterocyclic compound and the empty $\mathrm{d}$ orbital of the metal surface atoms. The high value of ( $\left.\mathrm{E}_{\text {номо }}\right)$ of the molecule indications its tendency to donate electrons to the acceptor molecules at low energy empty molecular orbitals and enhance the inhibition efficiency. The lower $\mathrm{E}_{\mathrm{LUMO}}$ values refer to its ability to accept electrons. When value $\Delta \mathrm{E}_{\text {gap }}$ decreases, the reactivity of L-Tryptophan inhibitor increases, as a result increase the inhibition efficiency of it ${ }^{20}$. Values of molecular parameters in gas and aqueous phases were listed in Table- 5 .

\begin{tabular}{|c|c|c|c|c|}
\hline $\begin{array}{c}\mathrm{T} \\
{[\mathrm{K}]}\end{array}$ & $\begin{array}{c}\mathrm{K}_{\mathrm{ads}} \\
{\left[\mathrm{M}^{-1}\right]}\end{array}$ & $\begin{array}{c}-\Delta \mathrm{G}^{\mathrm{o}}{ }_{\mathrm{ads}} \\
{\left[\mathrm{kJ} \cdot \mathrm{mol}^{-1}\right]}\end{array}$ & $\begin{array}{c}-\Delta \mathrm{H}^{\mathrm{o}}{ }_{\mathrm{ads}} \\
{\left[\mathrm{kJ} \cdot \mathrm{mol}^{-1}\right]}\end{array}$ & $\begin{array}{c}\Delta \mathrm{S}^{\mathrm{o}} \text { ads } \\
{\left[\mathrm{J} \cdot \mathrm{K}^{-1} \cdot \mathrm{mol}^{-1}\right]}\end{array}$ \\
\hline 293 & 2739.73 & 29.07 & \multirow{5}{*}{1.293} & \multirow{5}{*}{94.4} \\
\hline 298 & 2583.98 & 29.42 & & \\
\hline 303 & 2409.64 & 29.73 & & \\
\hline 308 & 2427.18 & 30.24 & & \\
\hline 313 & 2710.03 & 31.02 & & \\
\hline
\end{tabular}

Table-4: Thermodynamic functions for L-tryptophan adsorption on the surface of carbon steel alloy in $3.5 \% \mathrm{NaCl}$ 
RASĀYAN J. Chem.

Vol. 10 | No. 3 |815 - 824 | July - September | 2017

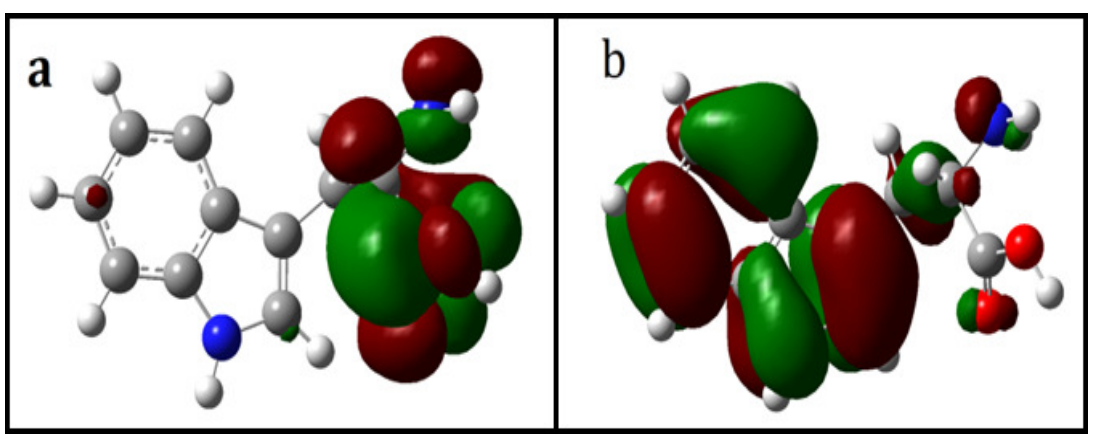

Fig.-8: (a) the energy of lowest unoccupied molecular orbital ( $\mathrm{E}_{\mathrm{LUMO}}$ ) and (b) the energy of highest occupied molecular orbital( $\mathrm{E}_{\text {номо }}$ ) of L-tryptophan.

Table-5: Quantum parameters of L-tryptophan in gas and aqeouse phases

\begin{tabular}{c|c|c}
\hline Terms & gas phase & aqeouse phase \\
\hline$-E_{\text {LUMO }}(\mathrm{ev})$ & 0.2969 & 0.0174 \\
\hline$-\mathrm{E}_{\text {HOMO }}(\mathrm{ev})$ & 5.5523 & 5.2642 \\
\hline$\Delta \mathrm{E}(\mathrm{ev})$ & 5.2555 & 5.2467 \\
\hline$\mu(\mathrm{Debye})$ & 3.6237 & 3.0281 \\
\hline$-\mathrm{E}_{\text {total }} \times 10^{5}\left(\mathrm{kcal} . \mathrm{mol}^{-1}\right)$ & 4.2833 & 4.2832 \\
\hline$\chi(\mathrm{ev})$ & 2.9246 & 2.6408 \\
\hline$\gamma(\mathrm{ev})$ & 2.6277 & 2.6234 \\
\hline$\Delta \mathrm{N}(\mathrm{ev})$ & 0.7755 & 0.8308
\end{tabular}

CONCLUSION

L-tryptophan was considered to be good eco-friendly inhibitor for carbon steel corrosion in alkaline saline solution with maximum inhibition efficiency of $71.72 \%$ at $10^{-2} \mathrm{~mol}$. $\mathrm{L}^{-1}$ inhibitor concentration and temperature of $293 \mathrm{~K}$. Potentiostatic studies revealed that L-tryptophan acted as anodic type inhibitor; also the corrosion process of carbon steel in studied environment was kinetically controlled. Furthermore, the kinetic data indicated that the corrosion of steel was both easier and faster in the absence of L-tryptophan as compared with corrosion in presence of it .On the other hand, Ltryptophan inhibited the corrosion of carbon steel through physical adsorption. The inhibiting function was permitted on the thermodynamic grounds of the adsorption process as indicated by the negative $\Delta \mathrm{G}^{\circ}$ ads values. Finally, a correlation has been obtained between experimental inhibition efficiency and some quantum chemical parameters studied namely: $\mathrm{E}_{\text {Hомо }}$, $\mathrm{E}_{\mathrm{LUMO}}, \mu, \mathrm{E}_{\mathrm{total}}, \chi, \gamma$ and $\Delta \mathrm{N}$ for both gas and aqueous phases.

\section{REFERENCES}

1. A. S. Fouda, Y. M.Abdallah and D.Nabil, International Journal of Innovative Research in Science, Engineering and Technology, 5(10), 12965 (2014).

2. Y. Mahendra, K. S. Tarun and P.Taniya, Journal of Molecular Liquids, 212, 731(2015).

3. A.S.Raja, S.Rajendran, J.Sathiyabama, V.Prathipa, I. N. Karthika and A.Krishnaveni, Int. J. Nano. Corr. Sci. Eng., 2(5), 25 (2015).

4. V. Prathipa and A. S.Raja, J. Chem. Bio. Phy. Sci., 5(2), 1585 (2015).

5. C. Verma, M. A. Quraishia and A. Singh, Journal of Molecular Liquids, 212, 804 (2015).

6. K. R. Ansari, M. A. Quraishi and A. Singh, Measurement, 76, 136 (2015).

7. O. Kassou1, M. Galai, R. A. Ballakhmima, N. Dkhireche, A. Rochdi, M. Ebn Touhami, R. Touir and A. Zarrouk, J. Mater. Environ. Sci., 6(4), 1147 (2015).

8. M. Mobin, P. Mosarrat and M. Alam Khan, Recent Research in Science and Technology, 3,40 (2011). 
9. E. Garcia-Ochoa, S. J. Guzmán-Jiménez, J. Guadalupe Hernández, P.Thangarasu, M.V. José and C.Julián, Journal of Molecular Structure, 1119, 314 (2016).

10. A. A.Ahmed, H. K.Abdul Amir, K. M.Abdulhadi Abu Bakar, K. H. Chong and J. Sutiana, Materials , 7, 787 (2014).

11. J.Bincy, J. Sam, J.Abraham and B. Narayana, Indian Journal of Chemical Technology, 17, 366 (2010).

12. M. Mohammad, Z.Saman and P.Mosarrat, Journal of Molecular Liquids, 216, 599 (2016).

13. M. Yadav, S. Kumar, N. Tiwari, I. Bahadur and E.E. Ebenso, Journal of Molecular Liquids, 212, 151 (2015).

14. O. Y. Ayşe, T.Esra, D. M.Başak, K.Gülfeza and Y.Birgül, Journal of Molecular Liquids, 218, 384 (2016).

15. Y.Mahendra, G.Laldeep, K.Nilam and Y. Premanand, Journal of Molecular Liquids,216,78 (2016).

16. S.Priyanka and M. A. Quraishi, Measerment, 86, 114 (2016).

17. G.Mohamed, B. Ahmad and Z. Basem, Research on Chemical Intermediates,41,9885 (2015).

18. M. A. Bedair, Journal of Molecular Liquids, 219, 128 (2016).

19. Y.Mahendra, K. S. Tarun and P.Taniya, Journal of Molecular Liquids, 212, 731 (2016).

20. M. E. Belghiti, Y. Karzazi, A. Dafali, I. B. Obot, E. E. Ebenso, K. M. Emrane, I. Bahadur, B. Hammouti and F. Bentiss, Journal of Molecular Liquids, 216, 874 (2016).

[RJC-1751/2017] 